\title{
The electrochemical surface modification of nitinol for inhibition of nickel elimination
}

\author{
A.I. Shcherbakov, I.V. Kasatkina, I.G. Korosteleva, V.E. Kasatkin, \\ L.P. Kornienko and V.N. Dorofeeva
}

\begin{abstract}
A.N. Frumkin Institute of Physical Chemistry and Electrochemistry, Russian Academy of
Sciences, Leninsky pr. 31, 119071 Moscow, Russian Federation

E-mail: scherbakov@ipc.rssi.ru
\end{abstract}

\begin{abstract}
Nitinol, an alloy with a shape memory effect, is used in many high-tech developments, in particular in medicine as self-expanding material for vascular endoprostheses, stents, etc. However, a high nickel content in the alloy may be undesirable for biocompatibility and therefore requires the use of certain processing products to reduce the rate of formation of $\mathrm{Ni}^{2+}$ as a result of corrosion processes in the presence of alloy with body tissues. To solve this problem, the possibilities of Nitinol electrochemical treatment based on the different rates of dissolution of the alloy components from the surface layer were investigated. The processes of potentiostatic etching of NiTi in sulphate solutions, which provide selective dissolution of one alloy component and accumulation of another one in the surface layer, have been investigated. Using the polarization curves methods and the electrochemical impedance spectroscopy, it has been discovered. The possibility of selective etching of nickel from the surface layer of Nitinol with the simultaneous formation of titanium dioxide is shown. The high insulating properties of $\mathrm{TiO}_{2}$ film formed on the alloy surface as a result of oxidation at a controlled potential, inhibits the release of nickel from the surface layer and the accumulation of $\mathrm{Ni}^{2+}$ ions in a corrosive, like the physiological solution.
\end{abstract}

Keywords: Nitinol, selective dissolution, passivation, impedance, protection.

Received: June 26, 2019. Published: September 17, 2019

doi: $\underline{10.17675 / 2305-6894-2019-8-3-19}$

Nitinol alloy based on titanium nickelide NiTi has the property of restoring the original shape of a product after appropriate heat treatment (the shape memory effect) and also is a superelastic material $[1,2]$. The combination of these unique properties with high strength, corrosion resistance in many environments determines the applications of this modern high-tech material in various fields: from space and aviation technology to agriculture. In particular, it is applied in medical technology as a "smart" self-expanding material for vascular endoprostheses, stents, valves, bone and dental implants, braces, etc. [2-4]. However, long term corrosion tests of NiTi in simulated physiological solutions have shown the accumulation of $\mathrm{Ni}^{2+}$ ions in a fluid, which may be undesirable for the biocompatibility of Nitinol based products with body tissues [5-7]. 
Obviously, to reduce the release of $\mathrm{Ni}^{2+}$ ions from the intermetallic compound, it is necessary to modify the alloy surface, forming a dense protective layer with a minimum nickel content, but without affecting the structure of the base material, which provides a shape memory effect. For this purpose, we studied the application of the electrochemical treatment at controlled potentials, which allows changing the ratios of NiTi components in a thin surface layer by means of selective dissolution.

Under conditions of spontaneous passivity, a protective film is formed on the surface of the intermetallic compound, consisting of mixed oxides of titanium and nickel [7]. Pure titanium dioxide film is a high-resistance semiconductor. The presence of nickel imparts electronic conductivity to the oxide on the intermetallic compound, which reduces the resistance and protective properties of the surface layer. To inhibit the ingress of unwanted $\mathrm{Ni}^{2+}$ ions into the corrosive environment, it is necessary to reduce significantly the concentration of this component in the surface layer, thereby forming a film consisting mainly of titanium dioxide.

Electrochemical modification of the alloy surface has been carried out in sulfate solutions: in neutral $0.5 \mathrm{M} \mathrm{Na}_{2} \mathrm{SO}_{4}, \mathrm{pH}=5.6$, acidified $\left(0.5 \mathrm{M} \mathrm{Na}_{2} \mathrm{SO}_{4}, \mathrm{pH}=2\right.$ with addition of $\left.\mathrm{H}_{2} \mathrm{SO}_{4}\right)$ and acidic $\left(2.5 \mathrm{M} \mathrm{H}_{2} \mathrm{SO}_{4}\right)$ media. The potentiodynamic curves for the alloy allow determining the potential regions that provide selective dissolution of its components in these media. The potentials were measured relative to a saturated silver chloride reference electrode, contacting with the solutions through a bridge, preventing $\mathrm{Cl}^{-}$ions penetration to the cell. Potentials are given relative to SHE. The relatively high sweep rate of $100 \mathrm{mV} / \mathrm{s}$ has been used to reduce the change in surface state during the curves registration. The most informative were the anodic polarization curves in $2.5 \mathrm{M} \mathrm{H}_{2} \mathrm{SO}_{4}$.

The comparison of the curves for NiTi intermetallic compound and for its pure components: titanium and nickel are shown in Figure 1. Two characteristic regions are observed on the NiTi curve: a narrow peak at the potentials range $E=-150.0 \mathrm{mV}$ and a dual wide peak in the potential range of +150 to $+450 \mathrm{mV}$. Obviously, the first peak with a maximum at $E=-50 \mathrm{mV}$ can be associated with active dissolution of titanium from the alloy. For pure titanium, a similar peak is shifted slightly to the cathodic direction (the maximum is at $E=-200 \mathrm{mV}$ ) and at potentials more noble than $0 \mathrm{mV}$, titanium is already completely passive [8]. The second peak for the intermetallic compound can be interpreted as the dissolution of nickel component from the alloy, taking into account the potential region and the characteristic twin peak shape. A similar behavior is observed on the polarization curve for pure nickel, although the current densities on this sample are an order of magnitude higher compared with the intermetallic compound. This is probably due to the presence of a passive $\mathrm{TiO}_{2}$ film on NiTi sample at these potentials, which prevents active dissolution of nickel. At higher potentials, nickel is also completely passive [9]. It should be noted that these data are similar to the results obtained earlier for different titanium-nickel alloys [10-13]. 


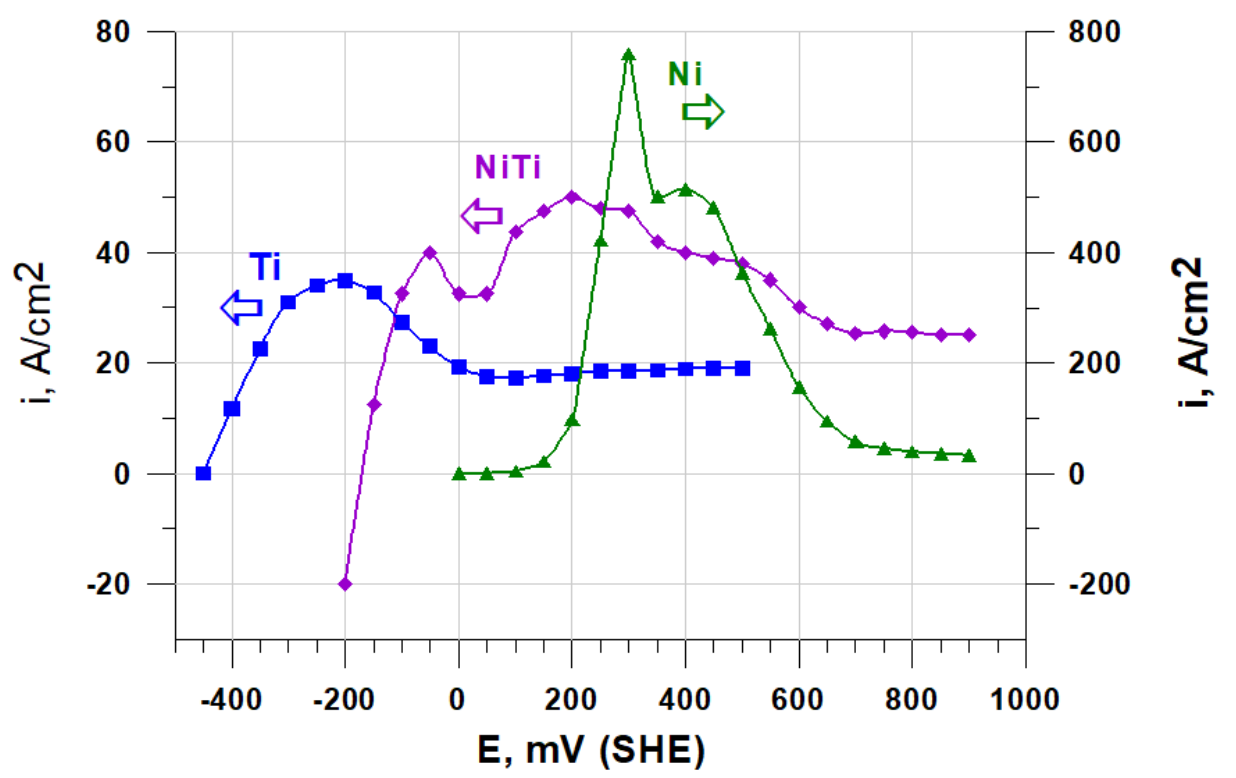

Figure 1. Anodic polarization curves $100 \mathrm{mV} / \mathrm{s}$ in $2.5 \mathrm{M} \mathrm{H}_{2} \mathrm{SO}_{4}, 30^{\circ} \mathrm{C}$ for NiTi intermetallic compound and pure Ti and Ni.

Thus, the active dissolution of the alloy components occurs at essentially different potentials and it is possible to select the potential range, where one of the components dissolves and the other is stable. During one hour potentiostatic exposure at the potential of the first peak $E=-50 \mathrm{mV}$, titanium is selectively dissolves from the surface layer of the intermetallic compound and nickel accumulates. As a result, the peak of titanium dissolution on Figure 2, curve 1 disappears almost completely and the peak of nickel dissolution increases significantly. On the contrary, after one hour potentiostatic treatment at $E=+300 \mathrm{mV}$, the peak of titanium active dissolution is well apparent on Figure 2, curve 2 and the peak of nickel dissolution practically disappears.

These results show that it is possible to provide a preferential dissolution of titanium or nickel component from the surface layer on Nitinol, depending on the potential at which the alloy is held. Polarization at the potentials range, where active dissolution of nickel take place and at the same time titanium is in the passive state, leads to the enrichment of the surface layers with titanium. The surface film after such treatment consists mainly of $\mathrm{TiO}_{2}[8,14]$. The long exposure of the intermetallic compound at the potentials of titanium active dissolution, on the contrary, leads to the enrichment of the surface layer with nickel.

The results of Electrochemical Impedance Spectroscopy (EIS) of NiTi alloy samples at the Open Circuit Potential (OCP) confirm the significant change in the surface states after selective dissolution of one and the accumulation of another component during one hour potentiostatic treatment. Nyquist plots for $\mathrm{NiTi}$, both in the initial state and after processing, are slightly flattened semicircle arcs. An equivalent electrical circuit for such state is a parallel connection of a resistor $R$, responsible for charge transfer processes, and a constant phase element $C P E$, which simulates the capacitive factors of the system. 


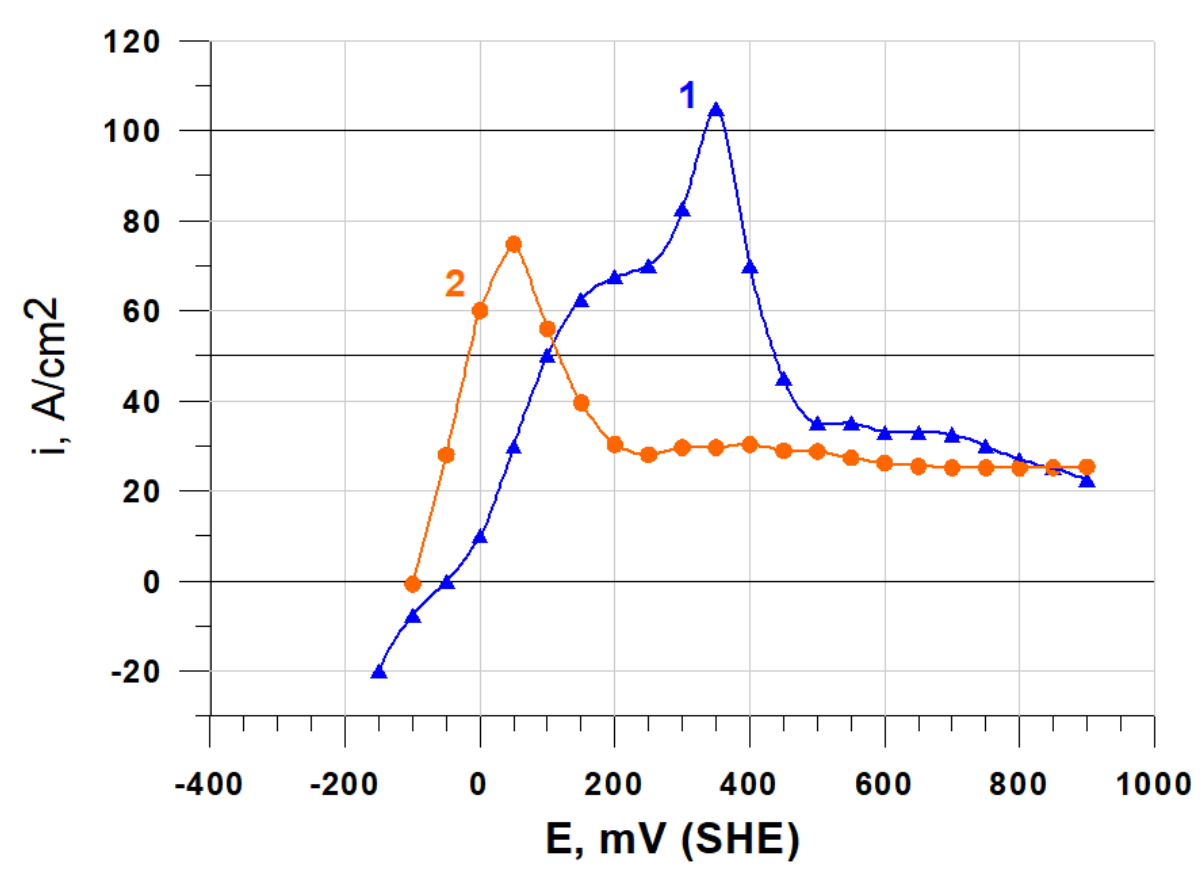

Figure 2. Anodic polarization curves $100 \mathrm{mV} / \mathrm{s}$ in $2.5 \mathrm{M} \mathrm{H}_{2} \mathrm{SO}_{4}, 30^{\circ} \mathrm{C} .1-\mathrm{NiTi}$ after 1 hour polarization at $E=-50 \mathrm{mV}$ (selective dissolution of Ti); $2-\mathrm{NiTi}$ after 1 hour polarization at $E=+300 \mathrm{mV}$ (selective dissolution of $\mathrm{Ni}$ ).

Table 1. The nominals of the equivalent electrical circuit elements.

\begin{tabular}{|c|c|c|c|}
\hline $\mathrm{Z}_{\mathrm{CPE}}=\mathrm{A}_{\mathrm{CPE}}^{-1}$ & $\begin{array}{l}\text { NiTi without } \\
\text { treatment }\end{array}$ & $\begin{array}{c}\text { After } E=-50 \mathrm{mV} \\
\text { Selective dissolution } \\
\text { of titanium. Nickel is } \\
\text { accumulated. }\end{array}$ & $\begin{array}{c}\text { After } E=+300 \mathrm{mV} \\
\text { Selective dissolution } \\
\text { nickel. Titanium is } \\
\text { accumulated. }\end{array}$ \\
\hline $\boldsymbol{R}, \mathrm{Ohm} \cdot \mathrm{cm}^{2}$ & 1150 & 244 & 10465 \\
\hline $\mathrm{CPE} \boldsymbol{A}, \mathrm{Ohm}^{-1} \cdot \mathrm{cm}^{-2} \cdot \mathrm{s}^{n}$ & $219.8 \cdot 10^{-6}$ & $222.8 \cdot 10^{-6}$ & $64.3 \cdot 10^{-6}$ \\
\hline CPE $\boldsymbol{n}$ & 0.857 & 0.889 & 0.945 \\
\hline
\end{tabular}

For this kind of equivalent electrical circuit, the diameter of the Nyquist plot (Figure 3 ) is equal to the resistance $R$, which value is proportional to the corrosion process intensity. It can be seen that the semicircle size (and the resistance $R$ ) of the curve 2 after dissolution of titanium component is almost 5 times less than for the alloy without treatment. As a result, the enrichment of the surface with nickel, which has high electronic conductivity, takes place. On the contrary, after selective dissolution of nickel, the semicircle diameter of the curve 3 is almost an order of magnitude larger than for the initial state due to the formation on the surface a poorly conducting layer enriched with titanium dioxide. 


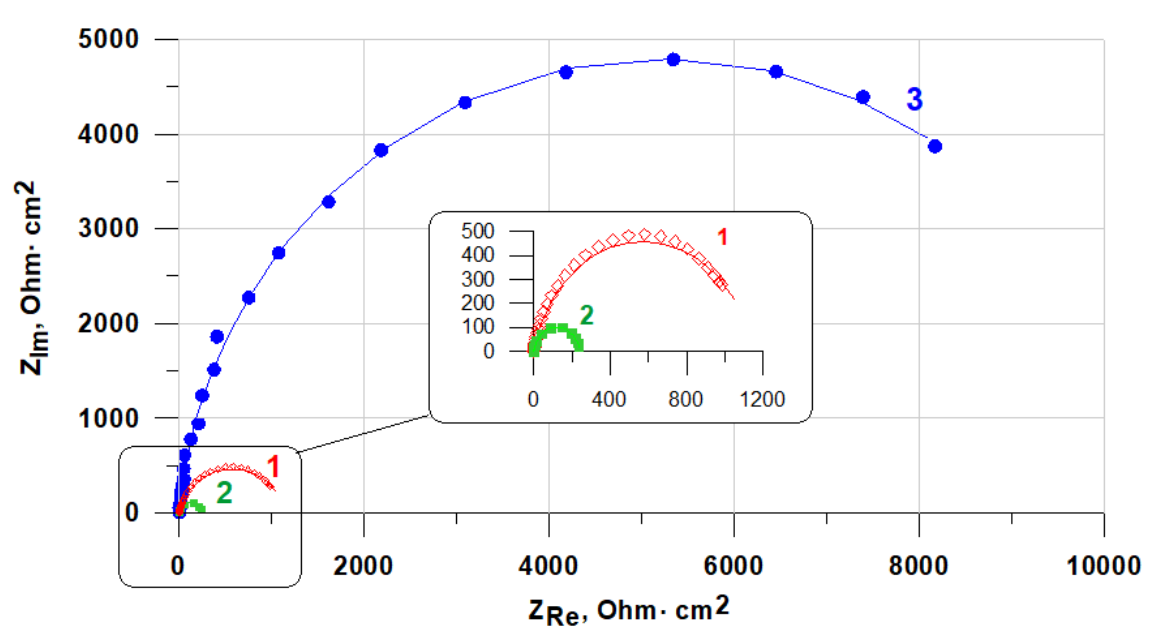

Figure 3. Nyquist plot for NiTi alloy samples in $2.5 \mathrm{M} \mathrm{H}_{2} \mathrm{SO}_{4}$. (1) without treatment; (2) after 1 hour at $E=-50 \mathrm{mV}$ (Titanium dissolution), (3) after 1 hour at $E=+300 \mathrm{mV}$ (Nickel dissolution). The signs represent the experimental points; the solid lines show the simulation results according to the equivalent electrical circuit.

The phase factors $n$ for the CPE element in all cases are close to unity, which makes possible to consider this element as a non-ideal capacitor and with a certain fraction of the approximation to count numerically it value in capacity units $\mathrm{F} / \mathrm{m}^{2}$. It is noteworthy that for samples containing nickel on their surface, the capacitance factors are almost the same (about $220 \mu \mathrm{F} / \mathrm{cm}^{2}$ ), and after pickling of nickel, the capacity decreases to $64 \mu \mathrm{F} / \mathrm{cm}^{2}$, probably due to the formation of a thicker titanium dioxide layer with high insulating properties. It should be noted that the phase factor $n$ for such a sample is higher than for two other samples, which indicates a more uniform surface state after nickel dissolution from the surface.

In such a way, these impedance measurements are fully consistent with the results of potentiodynamic curves studies and prove that after exposure at certain potentials in an acidic solution, the surface is depleted by one and is enriched by another component due to selective dissolution, which further affects the electrochemical and corrosion behavior.

In neutral (0.5 $\left.\mathrm{M} \mathrm{Na}_{2} \mathrm{SO}_{4}, \mathrm{pH}=5.6\right)$ and acidified ( $\left.0.5 \mathrm{M} \mathrm{Na}_{2} \mathrm{SO}_{4}, \mathrm{pH}=2\right)$ solutions the spontaneous passivity of Nitinol is observed already at a room temperature $\left(25^{\circ} \mathrm{C}\right)$. There are no characteristic peaks on the polarization curves and the curves are almost identical (Figure 4, curves 1 and 2). An increase in temperature to $90^{\circ} \mathrm{C}$ does not affect the spontaneous passivity in the neutral solution (Figure 4, curve 3), and only in the acidified solution at the same temperature the peak of nickel dissolution with characteristic splitting appears (Figure 4, curve 4). Unlike in acidic solution (2.5 $\left.\mathrm{M} \mathrm{H}_{2} \mathrm{SO}_{4}\right)$, titanium is practically insoluble under these conditions. 


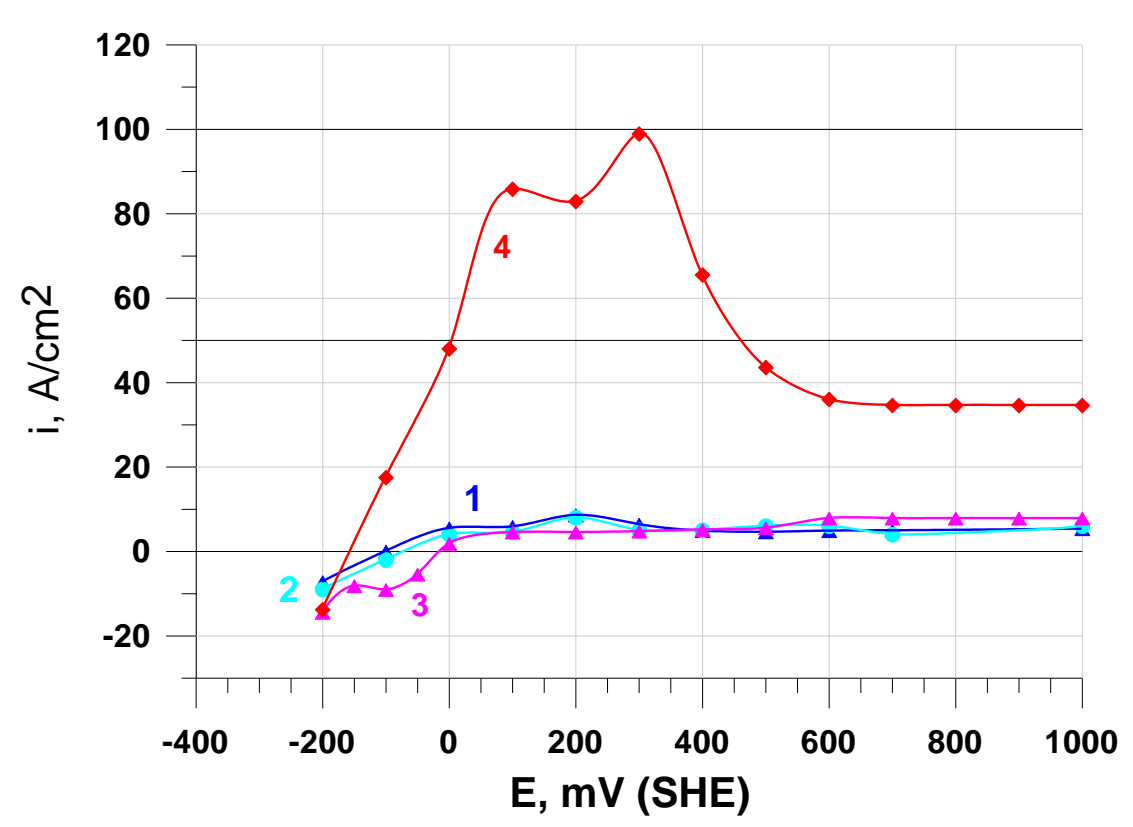

Figure 4. Anodic polarization curves of Nitinol in $0.5 \mathrm{M} \mathrm{Na}_{2} \mathrm{SO}_{4}$. (1) $\mathrm{pH}=5.6 / 25^{\circ} \mathrm{C}$; (2) $\mathrm{pH}=2 / 25^{\circ} \mathrm{C}$; (3) $\mathrm{pH}=5.6 / 90^{\circ} \mathrm{C}$; (4) $\mathrm{pH}=2 / 90^{\circ} \mathrm{C}$.

Since titanium accumulates during selective dissolution of nickel, later, when spontaneous passivity of such sample occurs, titanium dioxide will form predominantly on its surface, preventing corrosion in general and inhibiting nickel dissolution from the alloy, in particular. To confirm this, NiTi samples were polarized for 4 hours at $E=+300 \mathrm{mV}$ (in the region of active dissolution of $\mathrm{Ni}$ ) in neutral and acidified solutions at $90^{\circ} \mathrm{C}$, after which these samples were exposed for 18 days in $0.9 \% \mathrm{NaCl}$ medium. At the end of the experiment, the solution was analyzed for $\mathrm{Ni}^{2+}$ ions content using the photo spectroscopy method (the sensitivity no less than $10^{-7} \mathrm{~g} / \mathrm{cm}^{3}$ ). In both cases (after proceeding in neutral and acidified solutions), nickel was not detected. Taking into account the ratio of the sample area to the solution volume about $0.01 \mathrm{~cm}^{2} / \mathrm{cm}^{3}$, it is possible to estimate that the maximum rate at which $\mathrm{Ni}^{+2}$ ions may enter the solution will be less than $0.2 \mathrm{mg} / \mathrm{cm}^{2}$ per year. More accurate results require additional research.

Thus, it was found that, by determining suitable conditions for potentiostatic selective etching, it is possible to reduce the surface concentration of a certain component of Nitinol with simultaneous accumulation of the other one. When nickel is dissolved selectively, a protective layer consisting of titanium dioxide is formed on the surface of the NiTi alloy, which inhibits the penetration of nickel ions into the solution. Such electrochemical modification of the surface layer on the intermetallic compound does not violate its physical properties causing the shape memory effect, which allows using this treatment in the field of medical technology to solve the problem of biocompatibility of Nitinol products. 


\section{References}

1. I.I. Kornilov, Titanium, Nauka, Moscow, 1975, 309 (in Russian).

2. D. Stoeckel, Nitinol medical devices and implants, Min. Invas. Ther. \& Allied Technol., 2000, 9, no. 2, 81-88. doi: 10.3109/13645700009063054

3. S.A Muslov, I.V Yarema and O.V. Danilevskaya, Nitinol as a new-generation medical material, Sovremennye naukoemkie tekhnologii, 2007, 11, 55-56 (in Russian).

4. C. Trepanier, R. Venugopalan and A.R. Pelton, Corrosion Resistance and Biocompatibility of Passivated NiTi, in Shape Memory Implants, Ed. L'H. Yahia, Springer, 2000, 35-45. doi: 10.1007/978-3-642-59768-8_3

5. V.A. Engovatov, Unusual properties of Nitinol and its applications in medicine, $G B O U$ VPO Saratovskii GMU im. V.I. Razumovskogo Minzdrava Rossii, kafedra propedevtiki stomatologicheskikh zabolevanii, Byulleten' meditsinskikh Internet-konferentsii (ISSN 2224-6150), 2015, 5, no. 11 (in Russian).

6. L. Zhu, C. Trepanier, A.R. Fino and J. Pelton, Oxidation of Nitinol and Its Effect on Corrosion Resistance, Med. Device Mater., Proc. Mater. Processes Med. Devices Conf., 2003.

7. W. Hansen, L.T. Fuhr, L.M. Antonini, D.J. Villarinho, C.E.B. Marino and C. de Fraga Malfatti, The Electrochemical Behavior of the NiTi Alloy in Different Simulated Body Fluids, Mater. Res., 2015, 18, no. 1, 184-190. doi: 10.1590/15161439.305614

8. A.G. Akimov, E.N. Paleolog and A.Z. Fedotova, A study on the composition of oxide layers on Ti-Ni alloys, Elektrokhimiya, 1979, 15, no. 7, 1080-1094 (in Russian).

9. N.D. Tomashov, Titanium and its corrosion-resistant alloys, Moscow, Metallurgiya, 1985, 80 (in Russian).

10. B. Kulusic, Lj. Krstulovic and B. Kulusic, Passivation of Nickel in Sulfuric acid, International Society of Electrochemistry $37^{\text {th }}$ Meeting, Vilnius, 1985, 1, 410-412.

11. I.V. Kasatkina, A.I. Shcherbakov and R.Kh. Zalavutdinov, Effect of the chemical composition of Ti-(0.5-3\%)Ni alloys on their general and selective corrosion, Zashch. Met., 1994, 30, no. 2, 133-138 (in Russian).

12. A.I. Shcherbakov, I.V. Kasatkina and N.D. Tomashov, Polarographic estimation of the accumulation of alloying components on a corroding surface of titanium alloys, Zashch. Met., 1994, 30, no. 5, 469-472 (in Russian).

13. A.I. Shcherbakov and I.V. Kasatkina, Enhancing the corrosion resistance of titanium by cathodic alloying with non-noble components, Korroz.: Mater., Zashch. (Corrosion: Materials, Protection), 2005, 11, 8-13 (in Russian).

14. J. Kim, J.K. Park, H.K. Kim, A.R. Unnithan, C.S. Kim and C.H. Park, Optimization of Electropolishing on NiTi Alloy Stents and Its Influence on Corrosion Behavior, $J$. Nanosci. Nanotechnol., 2016, 16, 1-7. doi: 10.1166/jnn.2016.13324 